\title{
Lenguas en la marquesina: análisis del paisaje lingüístico de barrios de la Ciudad de Buenos Aires
}

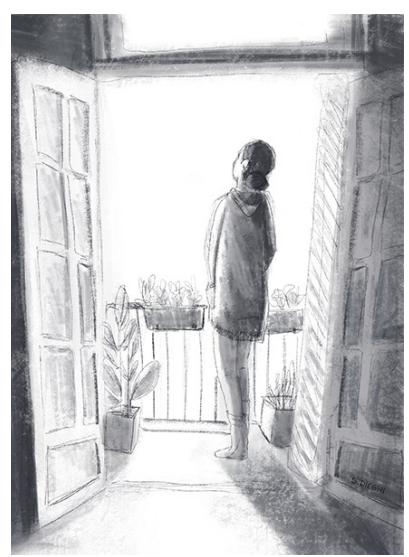

Natalia Bengochea

Universidad de Buenos Aires, Universidad Nacional de General Sarmiento,

Universidad Nacional de Tres de Febrero, Argentina

nibengochea@gmail.com

Trabajo recibido el 2 de abril de 2019 y aprobado el 27 de mayo de 2019.

\begin{abstract}
Resumen
La Ciudad Autónoma de Buenos Aires ha sido receptora de diversas olas inmigratorias, que delinearon su espacio de manera singular. Actualmente, la superdiversidad (Vertovec 2007) producto de las nuevas formas de movimientos migratorios y el contacto que establecen las personas a través de las nuevas tecnologías generan diferentes prácticas lingüísticas. Nos proponemos rastrear esas prácticas en la ciudad a través del estudio del paisaje lingüístico (Landry y Bourhis 1997; Itagi y Singh 2002) entendido como el lenguaje de lo escrito y lo audible en un territorio particular. El registro de las lenguas presentes en forma escrita - señalética, carteles publicitarios, letreros comerciales y de edificios gubernamentales, entre otros- en zonas de los barrios de Balvanera y Flores nos permite dar cuenta del impacto de la presencia de las comunidades migratorias que viven en esos lugares y el rol que cumplen las lenguas extranjeras como símbolo de internacionalización y prestigio. A su vez, el uso de estas lenguas en la cartelería expresa, en ciertos casos, una apropiación y un acceso desigual a las mismas. También consideraremos la coincidencia o no de estos usos con la normativa vigente sobre la presencia de las lenguas en la vía pública.
\end{abstract}

\section{Languages on the marquee: linguistic landscape analysis of Buenos Aires City neighborhoods}

\begin{abstract}
The city of Buenos Aires has received different waves of immigration that structure its urban space in a singular way. Nowadays, different linguistic practices emerge from the superdiversity (Vertovec 2007) that comes out of new migrations and new ways to communicate due to technology development. We attempt to trace those practices through a linguistic landscape approach (Landry y Bourhis 1997; Itagi y Singh 2002), known as the study of all the written and spoken languages on a given territory. We search commercial
\end{abstract}

\section{Palabras clave}

paisaje lingüístico legislación Ciudad Autónoma de Buenos Aires inmigración turismo

\section{Keywords}

linguistic landscape legislation Buenos Aires City immigration tourism 
shop signs, advertising billboards, public signs on government buildings and street signs on Balvanera and Flores in order to understand the impact of migratory communities and the place given to foreign languages as a symbol of global citizenship and prestige. Besides, the use of foreign languages in signs, sometimes, express an unequal access to them. We will consider how the city legislates about the presence of languages on the public spaces.

\section{Línguas na marquise: análise da paisagem lingüística dos bairros da cidade de Buenos Aires}

\section{Resumo}

A Cidade Autônoma de Buenos Aires tem recebido várias ondas de imigração, que delinearam seu espaço de uma maneira única. Atualmente, o produto da superdiversidade (Vertovec 2007) das novas formas de movimentos migratórios e o contato estabelecido pelas pessoas através de novas tecnologias geram diferentes práticas lingüísticas. Propomos traçar essas práticas na cidade através do estudo da paisagem lingüística (Landry e Bourhis 1997, Itagi e Singh 2002) entendida como a linguagem do escrito e do audível em um determinado território. O registo das línguas presentes em sinais de forma escrita, cartazes publicitários, sinais comerciais e edifícios governamentais, entre outros - nas áreas dos bairros de Balvanera e Flores permite-nos explicar o impacto da presença de comunidades migrantes que vivem em esses lugares e o papel das línguas estrangeiras como símbolo de internacionalização e prestígio. Por sua vez, o uso dessas línguas nos cartazes expressa, em certos casos, uma apropriação e um acesso desigual a eles. Consideraremos também a coincidência ou não desses usos com a regulamentação vigente sobre a presença de idiomas nas vias públicas.

\section{Introducción}

La importancia del estudio del paisaje lingüístico reside en que permite observar cómo los individuos, los grupos, las comunidades y el Estado organizan, intervienen y se apropian o no del espacio público a través de las huellas de escritura. Asimismo, es provechoso relevar los fenómenos de contacto entre lenguas, las "mezclas" y la jerarquía con la que se incluyen, por ejemplo, en la fachada de un local comercial. Constituye un campo propicio para analizar el valor y las representaciones otorgadas a las diferentes lenguas a partir de la manera y la función con la que se las utiliza. Así como se estudia la presencia de las lenguas en el paisaje también es importante considerar las implicaciones de la ausencia de las mismas.

En este artículo, relevaremos un registro de las lenguas presentes en forma escrita -señalética, carteles publicitarios, letreros comerciales y de edificios gubernamentales, entre otros- a fin de dilucidar de qué manera se plasma la diversidad en zonas de los barrios de Balvanera y Flores. El mismo se realizó entre los meses de junio y agosto de 2016. Vale aclarar que se trata de un acercamiento exploratorio que busca dar cuenta de las lenguas que se introducen en el paisaje lingüístico correspondiente a las áreas especificadas. Para ello se seleccionaron carteles que tienen mensajes en lenguas diferentes al español en los espacios previamente delimitados -más adelante explicaremos los criterios con los que se ha hecho este recorte- En tanto nuestro interés se centra en identificar la presencia

\section{Palavras-chave}

paisagem lingüística legislação

Cidade Autônoma de Buenos Aires imigração turismo 
de las lenguas en el espacio público, consideramos, en un sentido amplio, la noción de cambio de código como el uso alternante entre dos lenguas, siendo los préstamos los casos particulares en los que el léxico se utiliza de manera frecuente en los discursos (Auliso y Peralta Frías 2013). La elección de la cartelería se realizó con el objetivo de mostrar las diferentes maneras y funciones que cumple la presencia de estas lenguas. Es decir, se tomaron ejemplos que permiten exponer la diversidad del paisaje lingüístico registrado. Se observarán las jerarquías que se establecen entre las lenguas en el caso de la señalética plurilingüe a partir del tamaño de la tipografía y la ubicación de las palabras escritas en cada lengua y los modos en los que el léxico alterna en el cambio de código. Previamente, nos detendremos a analizar la normativa vigente en la Ciudad Autónoma de Buenos Aires sobre el uso de las lenguas en el espacio público. A lo largo del artículo observaremos tensiones entre los supuestos ideológicos y prácticos que determina esta legislación y las acciones efectivas de los actores particulares.

\section{El paisaje lingüístico como objeto}

La investigación sobre el paisaje lingüístico toma como punto de partida la definición propuesta por Landry y Bourhis (1997) en uno de los estudios fundacionales de este campo. Los autores señalan que el paisaje lingüístico comprende el análisis de la visibilidad que se les da a las lenguas en los carteles comerciales y en el espacio público de un territorio específico. Su estudio permite entonces observar el lugar simbólico que una comunidad determinada les otorga a las diferentes lenguas, la vitalidad de las lenguas, la identidad lingüística de los diferentes grupos que las utilizan en el espacio público, sus representaciones sobre esas lenguas, los fenómenos de contacto entre lenguas y la organización del plurilingüismo.

Desde entonces, el paisaje lingüístico ha sido estudiado a través de diferentes disciplinas como la etnografía, la sociología, la semiología y la lingüística, entre otras, y con diversos alcances. Sobre estos enfoques, Blommaert (2016) advierte la necesidad de adoptar para su estudio una perspectiva etnográfica que implique un acercamiento histórico. Sostiene que solo de esta manera es posible dar cuenta de la estructura social como dinámica, fragmentada y compleja.

El alcance de los estudios sobre el paisaje lingüístico ha variado de acuerdo con los intereses de la investigación. Así, a lo largo de los años, su dominio ha abarcado desde el análisis de la mera cartelería y señalética hasta el análisis de los graffitis, la publicidad de la calle, incluso la que se encuentra en movimiento, hasta la presencia de las lenguas en las redes sociales y los dispositivos móviles o la presencia oral de las lenguas en un área determinada.

La presencia de las lenguas en el espacio público cumple dos funciones: la informativa y la simbólica. La función informativa refiere a mostrar que en esa área determinada se utiliza/n esa/s lengua/s para la comunicación; mientras que la simbólica visibiliza el estatus que una comunidad le otorga a esas lenguas presentes (Landry y Bourhis 1997). Las investigaciones advierten que es posible estudiar las señales y carteles en su relación con el tiempo (Blommaert y Maly 2016). Así, todo texto escrito indica el pasado en tanto se puede reconstruir su origen, los materiales, las condiciones y los grupos que lo produjeron; pero también señala al presente, informando 
qué lenguas aparecen en un espacio y los modos en los que se organiza la diversidad lingüística en un momento particular y, por lo tanto, qué lenguas se privilegian. A su vez, también se dirigen al futuro porque apuntan a una audiencia específica sobre la que buscan actuar. En este sentido, inciden en las representaciones, entendidas como una suerte de pantalla ideológica dotada de materialidad discursiva que se interpone entre las prácticas lingüísticas reales y la conciencia social de estas mismas, y que repercuten sobre las acciones y las prácticas discursivas de los hablantes (Arnoux y Bein 1999). Es decir, se trata de esquemas orientadores que atañen a la percepción y evaluación de las lenguas y distintos fenómenos lingüísticos y que son compartidos socialmente compartidos.

Pan (2007) amplía el estudio del paisaje lingüístico al retomar las propuestas que sugieren no solo considerar la difusión que tienen las lenguas, sino también su distribución dentro de la sociedad. Por lo tanto, incluye la noción de espacio y escala. A partir de la globalización, las lenguas se extienden rápidamente por todo el mundo, es decir, se potencia la diversidad lingüística horizontal. Ahora bien, esta expansión, indica Pan (2007), no tiene un correlato equitativo en los hablantes; contrariamente, se produce una distribución desigual, estratificada de las lenguas. Por esto, es necesario observar la diversidad lingüística en su escala vertical.

En lo que respecta al análisis del paisaje lingüístico de Argentina, específicamente, de la Ciudad de Buenos Aires, son pocas las investigaciones que se han llevado adelante. Se destacan dos estudios sobre el paisaje en instituciones públicas. Scherlis (2018) recupera una noción amplia de paisaje lingüístico en tanto considera la circulación de las lenguas escritas como orales en el Instituto de Investigaciones Judías (IWO). Estudia allí la presencia del idish y la vincula con el estatus y la vitalidad que tiene en la sociedad. Si bien se trata de una institución que se dedica a la enseñanza del idish, su poca presencia en la cartelería, las transliteraciones a la grafía latina y los escritos en español responden a la intención de no excluir a los visitantes, de ser "amigables" con ellos para integrarlos e invitarlos a conocer la lengua. Por el contrario, el idish aparece en los archivos, en los libros, los diccionarios y las clases, es decir, en espacios destinados a las personas que conocen el idioma o que lo están aprendiendo. Por su parte, Bonnin (2018) al reflexionar sobre los alcances de las investigaciones sobre el paisaje lingüístico, que tradicionalmente se restringe a lo meramente lingüístico dejando de lado los aspectos semióticos involucrados, propone la noción de paisaje discursivo. Este enfoque, por lo tanto, abarca lo lingüístico ${ }^{1}$ y lo semiótico. Bonnin (2018) releva la ausencia de una política sobre las lenguas en el ámbito de la salud en la ciudad llevada desde el Estado. El paisaje discursivo es intervenido, entonces, por corporaciones privadas como los laboratorios. La diversidad de lenguas y de variedades del español son atendidas por la iniciativa particular de los trabajadores y de los propios pacientes.

\section{La normativa sobre las lenguas en la ciudad}

La marcación del territorio con la presencia o no de determinadas lenguas puede estar condicionada por la normativa estatal referida al uso de las lenguas en el espacio público (Calvet 1997). Por lo tanto, para analizar el paisaje lingüístico de áreas de la Ciudad Autónoma de Buenos Aires es necesario relevar la reglamentación sancionada vigente que atañe a
1. Los aspectos lingüísticos son tenidos en cuenta en tanto se encuentran implicados en la materialidad semiótica. 
la presencia de las lenguas en la vía pública dado que la legislación nos permite observar la manera en la que la política estatal pretende regular las prácticas lingüísticas.

La ciudad regula la presencia de lenguas en el espacio público a través de dos textos legales: la ordenanza № 48965 (1994) y la ley "Idioma" N 477 (2000). La ordenanza № 48965 determina la obligatoriedad del uso de castellano para indicar el rubro de los comercios de la ciudad. En los considerandos del proyecto se explicitan los motivos de la normativa. Se trata de una respuesta ante la acción de los inmigrantes no hispanohablantes que concentran sus comercios en ciertos barrios y a la presencia de sus lenguas en el espacio público: "barrios enteros de nuestra ciudad son habitados por inmigrantes que habilitan sus comercios, y la indicación de rubro y nombre son escritos en su idioma de origen". En el texto se plantea que esta situación genera confusiones en la población local.

En 2000 la Legislatura porteña sanciona la Ley “Idioma” N 477 con el fin de regular el uso público de las lenguas. La normativa podría inscribirse en una tradición nacionalista sobre la lengua dado que vincula las nociones de "lengua", "identidad" y "nación". En consecuencia, promueve la protección de la "lengua nacional" de la terminología extranjera y de las otras lenguas para preservar la identidad nacional. Esta noción de idioma nacional evidencia una concepción de la ciudad como monolingüe, que a la vez se busca reforzar. En sus considerandos explica:

Que esta iniciativa tiene como objetivo concientizar a los habitantes de la Ciudad de la importancia de mantener la identidad que todos poseemos como habitantes de una Nación.

Que el lenguaje, lejos de ser un elemento más de identificación cultural, estructura el pensamiento y permite la identificación de cada uno de nosotros como pertenecientes a una cultura concreta.

Que en un mundo como éste, en el cual el proceso de globalización avanza en todos los ámbitos, debemos hacer un esfuerzo por rescatar las particularidades y la diversidad que existe en nuestra lengua castellana (Ley $N^{\circ} 4772000$ ).

Se trata de una normativa que, según expone en su artículo primero, se propone "defender para preservar el idioma nacional y evitar que se produzcan confusiones lingüísticas y discriminación". Resulta llamativo esto que se postula en el texto porque con el fin de evitar la discriminación el mismo se constituye en una reglamentación cuya puesta en práctica implica el no respeto a las diferentes culturas y lenguas. La propuesta de la ley pretende borrar la pluralidad cultural que conforma la ciudad. Así como a comienzos del siglo XIX, frente a los grandes grupos de inmigrantes que llegaban al país, se buscó homogeneizar a la población a través de la educación (Sinisi 1999), entre otras medidas, el paisaje lingüístico como elemento de la planificación lingüística constituye una herramienta para mantener una identidad nacional ante la diversidad que supone la globalización.

La sanción de esta ley indica que se reconoce la existencia de otras lenguas consideradas extranjeras que ocupan el espacio público de la ciudad. Sin embargo, ese reconocimiento se hace a fines de intervenir para defender una lengua que se entiende debe ser "pura", y, por lo tanto, no tiene que incorporar términos que son considerados pertenecientes a otras lenguas. Además, esta reglamentación expresa también la concepción determinista 
formulada por la hipótesis de Sapir y Whorf (Whorf 1956) que correlaciona la estructura de las lenguas con la visión de mundo. Desde esta perspectiva, se sostiene la importancia de defender las características del castellano porque se correspondería con determinada forma de pensar. Se trataría, entonces, de proteger una visión de mundo propia del castellano. Por el contrario, se postula que las otras diversidades deben ser anuladas 0 , al menos, evitadas.

En su artículo tercero la normativa que venimos analizando establece las reglas de la presencia de lenguas en las publicidades y carteles de la ciudad:

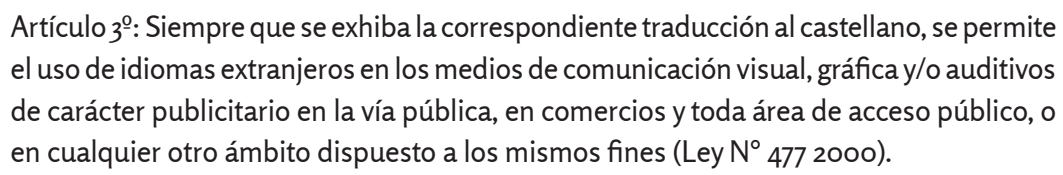

Entre las excepciones se encuentran los términos que no tienen traducción o que han sido aceptados por la Real Academia Española. La actitud purista de la norma vuelve a hacerse evidente en la consideración que hace del vocabulario reconocido como extranjero. Además, es de destacar que la normativa valore positivamente la autoridad de la Real Academia Española.

\section{Espacios de dos barrios de la ciudad}

La población migrante se distribuye de manera desigual en la ciudad. Esto se ha acrecentado en las últimas décadas, dando lugar a la formación de "barrios étnicos" en los que se da una alta concentración de inmigrantes. Entre estas poblaciones se genera una cohesión socioterritorial como respuesta a las dificultades que pueden encontrar los migrantes, que, en consecuencia, buscan la interrelación y el apoyo de sus compatriotas (Sassone y Mera 2007). Se van delineando así diferentes zonas con características particulares a partir de quienes las habitan.

Un área para estudiar por su diversidad demográfica es el barrio de Balvanera, cuyos límites son las avenidas Córdoba, Callao, Entre Ríos e Independencia, Sánchez de Bustamante, Avenida Díaz Vélez y Gallo. En su interior se pueden distinguir diferentes zonas, que incluso son reconocidas popularmente como barrios independientes con identidad propia. Entre ellos se encuentran "Once", caracterizado por los comercios mayoristas, y el "Abasto", que se distingue por ser hoy una zona turística con locales comerciales, confiterías y centros de tango.

En el presente trabajo vamos a analizar la construcción del paisaje lingüístico de este último. Como se trata de áreas que se estructuran con fines comerciales, no hay una especificación clara de sus límites. Para su estudio, tomamos como eje el centro comercial, el Shopping Abasto, centro comercial que se construyó sobre el antiguo Mercado del Abasto que había cerrado sus puertas en 1984 y fue rematado diez años después. Sobre este edificio, que se inauguró en 1998, se reestructuró el proyecto inmobiliario que modificó por completo la zona (Sassano 2001). A su alrededor había viviendas antiguas, algunas de las cuales estaban ocupadas ilegalmente. El proyecto se propuso revalorizar la zona y explotarla como área atractiva para el turismo. Se construyeron edificios torres, supermercados y hoteles de categoría (Sassano 2001). Con este mismo objetivo, se reafirmó como 
centro del tango, puesto que en esta zona vivieron grandes exponentes de la música ciudadana como Aníbal Troilo, Osvaldo Pugliese y Carlos Gardel. Es así que una de las calles aledañas que da al centro comercial fue nombrada Pasaje Carlos Gardel, donde además se incorporaron estatuas de músicos de tango. También en la zona abrieron milongas, escuelas de enseñanza del baile nacional y proliferaron tiendas de indumentaria típica. En esta misma dirección, los pasajes de esta zona fueron decorados con el filete porteño, estilo decorativo que utiliza colores fuertes y líneas que terminan en espirales, y se pintaron en las paredes letras de canciones de tango famosas.

En este artículo analizaremos la presencia de lenguas en la cartelería de los negocios de la zona que se encuentra entre las avenidas principales del lugar: la Av. Corrientes, Av. Pueyrredón, Av. Córdoba y la calle Billinghurst, que se encuentra a tres cuadras del Shopping Abasto. Esta área de la ciudad, como explicamos, a partir de la transformación del barrio se conforma como un núcleo turístico. Además de tener una tradición vinculada al tango, se distingue por ser uno de los espacios de la ciudad con mayor presencia de inmigrantes ${ }^{2}$. Uno de los grupos migratorios más antiguos en la zona es la comunidad judía, que se estableció en Argentina en la gran migración de principios del siglo XX. Entre 1907 y 1925 los migrantes judíos se asentaron en Balvanera, que se convirtió en el centro comercial y residencial más importante de esta comunidad (Feierstein 2006). Crearon allí redes sociales y culturales, edificaron sinagogas, escuelas, mutuales y negocios locales de comida tradicional. En este sentido, Feierstein señala que "Instituciones comunitarias y religiosas echan raíces en la zona y se convierten en símbolos visibles de etnicidad que distinguen el lugar" (Feierstein 2006, 147).

Entre los migrantes más recientes, los grupos mayoritarios en esta zona son los provenientes de países limítrofes y Perú (Dirección General de Estadística y Censos GCBA 2015). Durante los años noventa aumentó el número de migrantes bolivianos, paraguayos y peruanos, que se concentran espacialmente dentro de la ciudad (Cerruti 2005). En particular, los peruanos abrieron numerosos restaurantes y locales de su comida típica nacional. Otro grupo migrante presente en la zona corresponde a los coreanos que tienen aquí sus lugares de trabajo (Courtis, de la Fuente, Domínguez 2010) Y en la última década, inmigrantes africanos eligieron estas avenidas como lugar para la venta callejera ${ }^{3}$ y también escogieron el barrio como lugar para habitar (Struminger 2017).

\subsection{El paisaje lingüístico en la zona del Abasto}

Consideramos primero, la cartelería de comisarías en la que se reconoce la presencia de otras lenguas además del español. Si bien quedan fuera de la zona delimitada para construir el corpus a analizar, corresponden a las dos comisarías que tienen jurisdicción sobre el área estudiada. En 2016, en ambos carteles (Imagen 1) se indicaba en cuatro lenguas, español, inglés, hebreo y chino, que allí se encontraba la policía. Esto implicaba que desde una institución oficial se reconocía:

el inglés como lengua internacional y vinculado al turismo, y

las lenguas de comunidades inmigrantes, la judía y la china.

Sin embargo, a partir del traspaso de la Policía Federal de jurisdicción nacional al ámbito de la Ciudad Autónoma de Buenos Aires en 2017, se creó una nueva fuerza policial y, consecuentemente se cambió la cartelería
2. Según el informe Migraciones. Año 2015, la Comuna 3, correspondiente a los barrios de Balvanera y San Cristóbal, registra solo un $46,9 \%$ de porteños.
3. La venta callejera se desalojó al inicio de 2017 (Struminger 2017). 
de las comisarías. Se mantiene la presencia de diferentes lenguas pero ya no tiene en cuenta las de las comunidades migrantes del barrio sino que se incluyen lenguas europeas: inglés, francés e italiano.

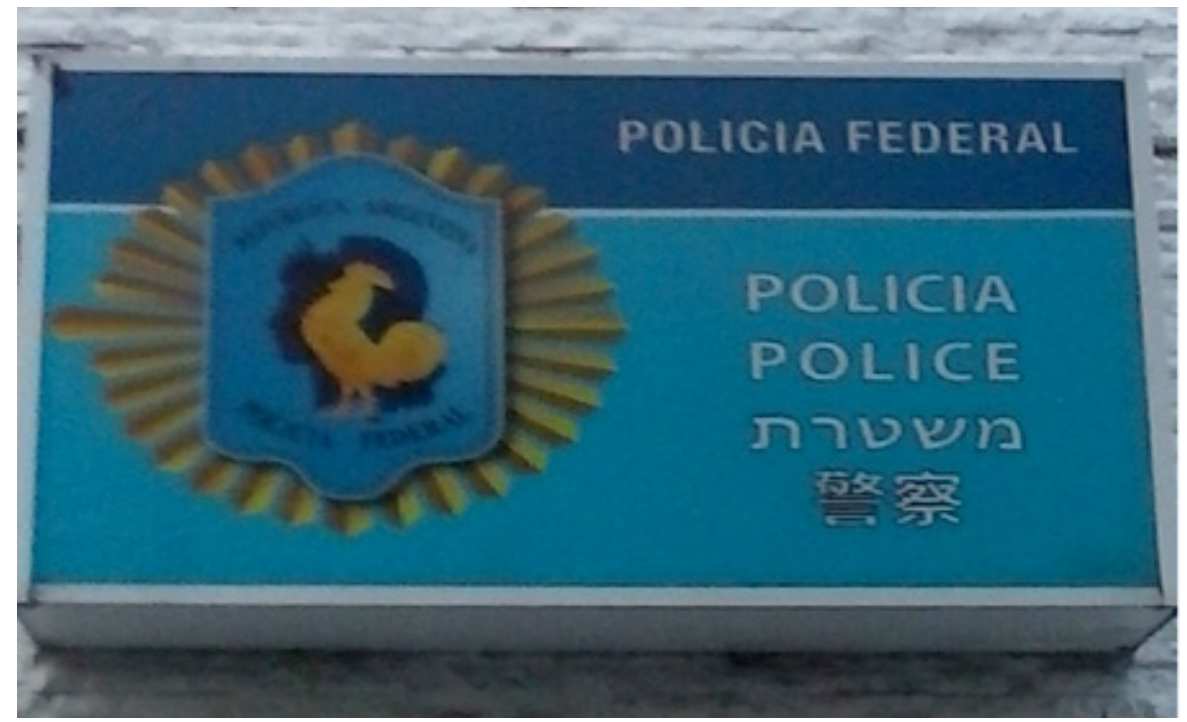

Imagen 1. Cartel de la comisaría $9^{\circ}$ de CABA anterior al paso de jurisdicción

En los templos de culto religioso, escuelas religiosas de la comunidad judía se observan carteles escritos con el alfabeto hebreo. La presencia del hebreo en este caso (Imagen 2) indexicaliza la comunidad judía, cumple la función de señalar que se trata de ámbitos destinados exclusivamente a esta comunidad. No hay indicaciones en español. Por su parte, cabe aclarar que si bien no se trata de señalizaciones lingüísticas, estos lugares también están identificados con bloques de cemento que se extienden en la vereda que corresponde a sus fachadas y a veces también con garitas de seguridad, como medida de protección tomada con posterioridad al atentado que se realizó contra la sede de AMIA-DAIA (Asociación Mutual Israelita Argentina - Delegación de Asociaciones Israelitas Argentinas) de 1994, ante la posibilidad de la ejecución de otro acto de violencia semejante.

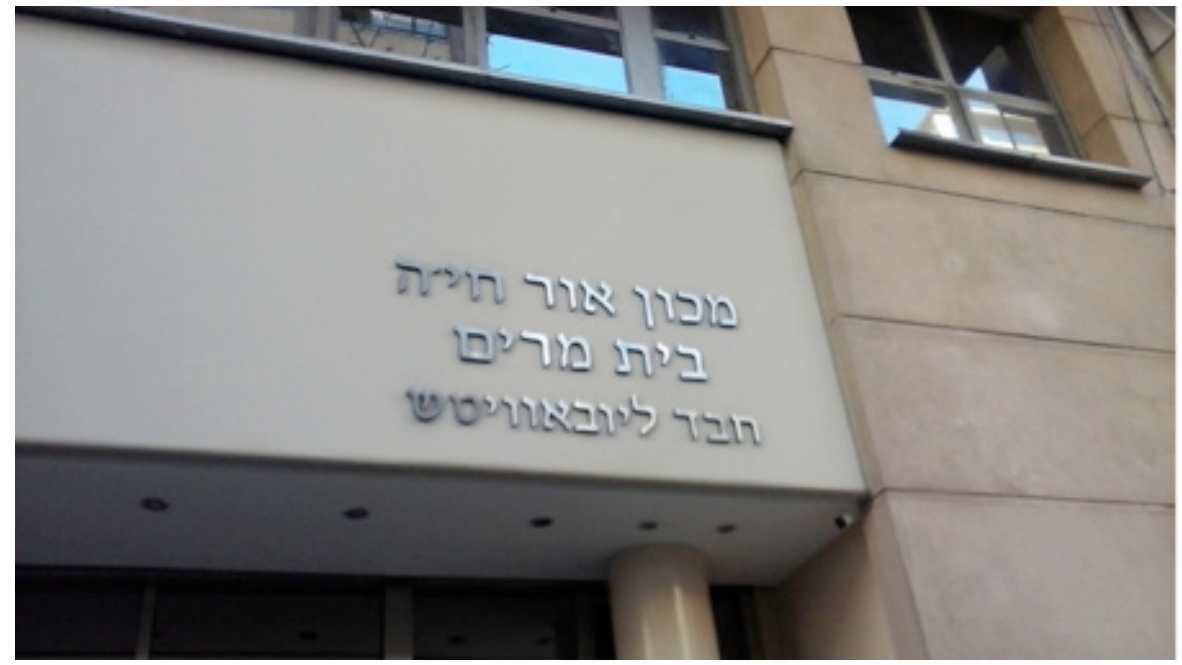

Imagen 2. Edificio de la Asociación Israelita Argentina Jabad Lubavitch señalizado con un cartel en hebreo, en Balvanera 
Algunos comercios del rubro alimenticio que venden comidas tradicionales o confeccionadas de la manera tradicional judía tienen nombres en hebreo escritos con alfabeto latino. En estos carteles todas las aclaraciones correspondientes al rubro y los productos de venta se encuentran en español. Un ejemplo de esto lo representa la fachada de la confitería Taam Tov (Imagen 3). El nombre hebreo, que quiere decir "buen gusto", funciona como índice de que allí se venden productos típicos judíos. Pero, como también hay otros productos, el hebreo no es la única lengua presente.

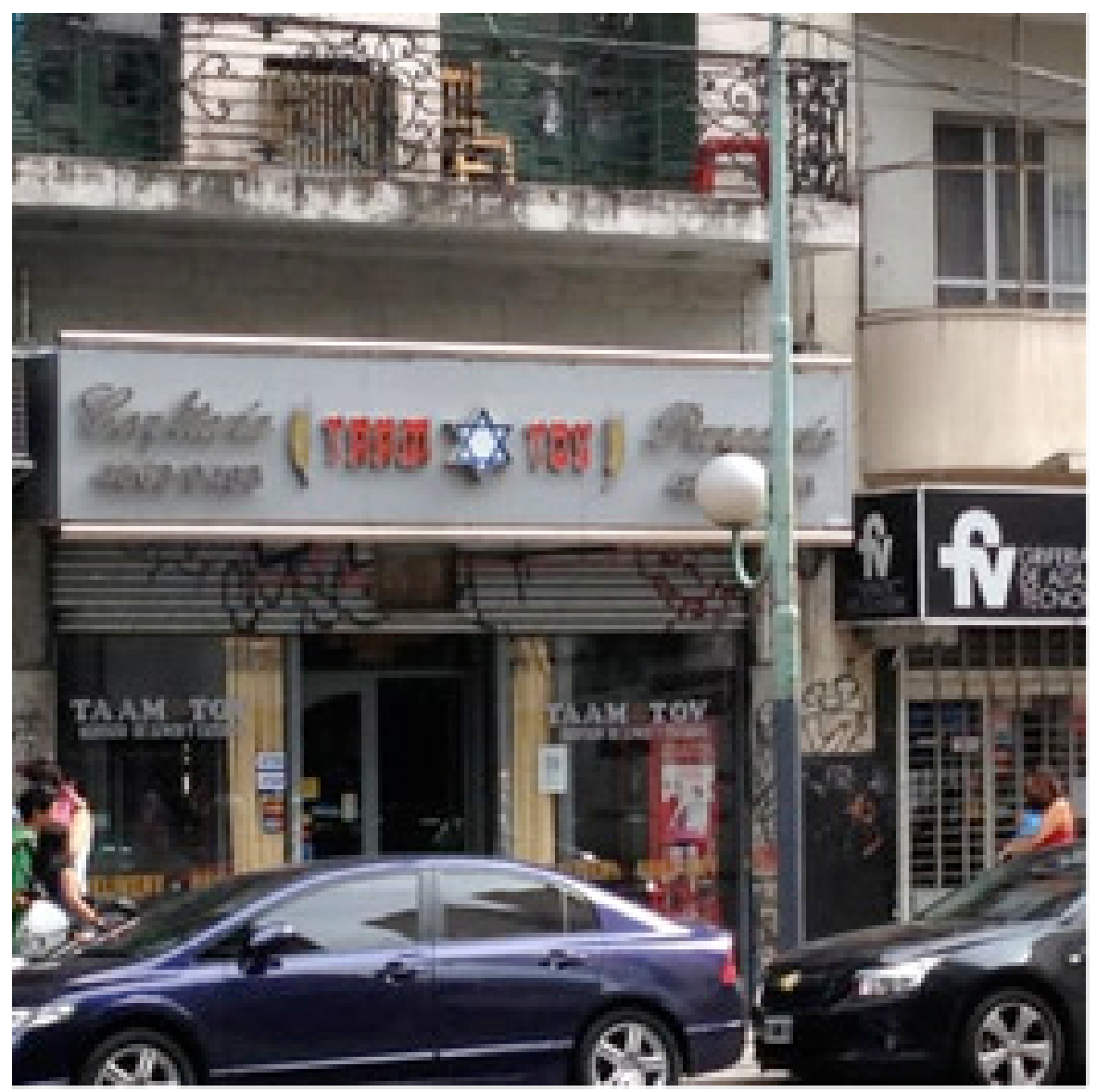

Imagen 3. Confitería Taam Tov, ubicada sobre la Av. Corrientes

Algo similar sucede con la librería Boker Tov (Imagen 4). Se señala con el nombre, que significa "buenos días", la pertenencia del local a la comunidad judía; pero en este caso, los productos se encuentran identificados en español para clientes que no se definen como hablantes de hebreo. 


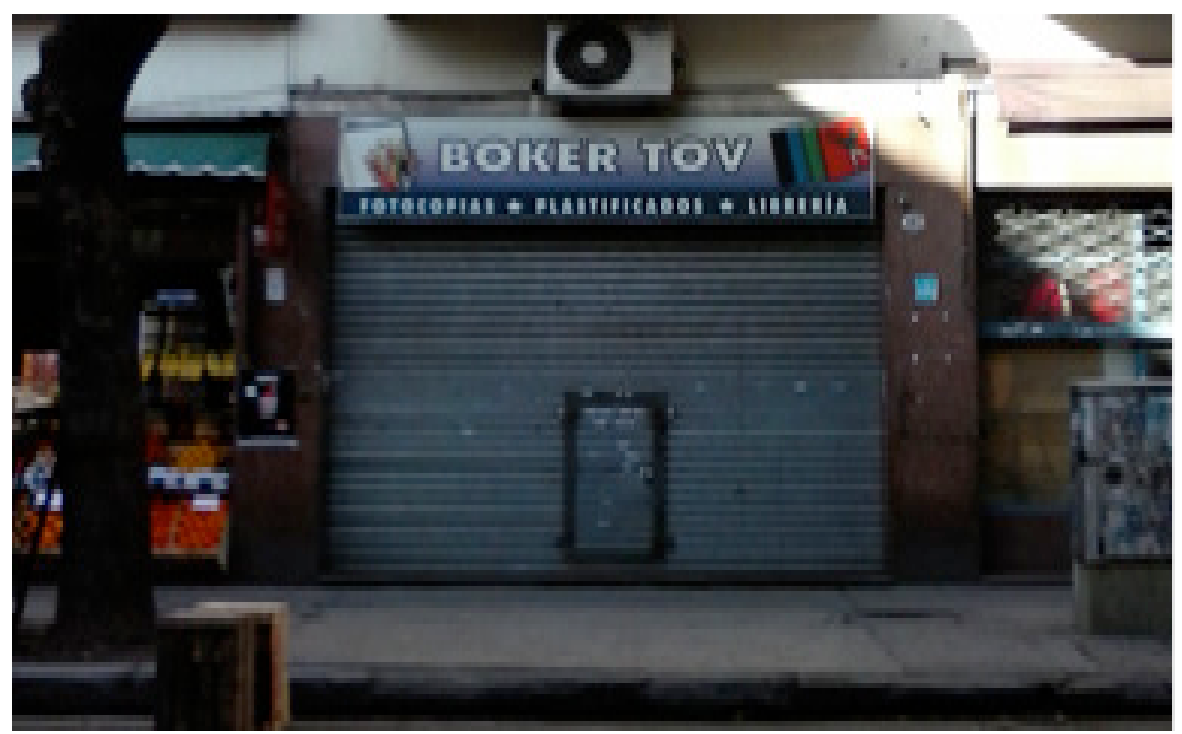

Imagen 4. Librería Boker Tov, ubicada sobre la calle Ecuador

En otros comercios como las carnicerías o restaurantes (Imagen 5), solo se indica en la vidriera a través de la palabra kosher o kasher que refiere que los alimentos siguen estos lineamientos de elaboración supervisados por una autoridad religiosa.

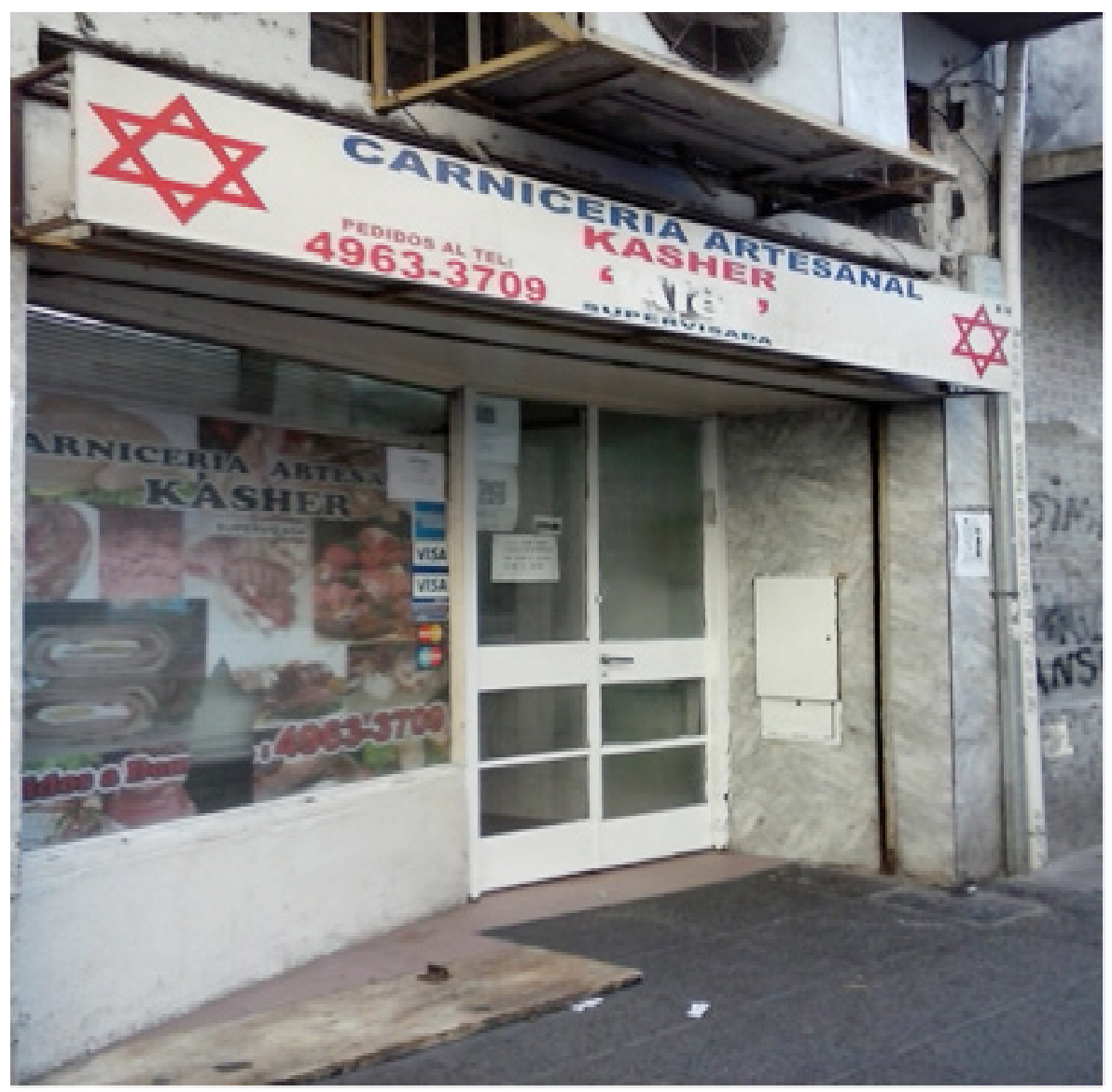

Imagen 5. Carnicería de la calle Ecuador 
Otra lengua presente en el paisaje lingüístico de esta zona es el inglés, particularmente en los locales comerciales. Analizaremos las características en las que se lo utiliza. Hay en el área publicidades de marcas de ropa o perfume internacionales que están escritas en esta lengua. Señalarían así la idea de que se compra el mismo producto en todo el mundo y, en forma simbólica, transmite que se trata de locales en los que se encontrarán productos de calidad global.

En otros carteles el inglés aparece con el español. Veamos un caso particular para analizar la relación y los roles de estas lenguas. En una parrilla (Imagen 6) ubicada a metros del Shopping Abasto, se combinan en la cartelería palabras en español y en inglés. Al tratarse de un local de la comida típica local, resulta evidente que la utilización del inglés busca atraer a turistas, mostrándose como un lugar turístico. El rubro "parrilla" está indicado en español y la tipografía en la que está escrita ocupa mayor tamaño en el cartel; sin embargo, el nombre del local y las aclaraciones están en inglés: Carlos Gardel St., Open, Abasto Grill and Steakhouse. A la derecha sobre la pared tienen un cartel en el que indican cortes de carne disponibles, la composición de un menú. Entre todas estas palabras en español, en un lugar central y con letras mayúsculas se indica: $A L L$ INCLUSIVE. Es posible observar que en el farol de la entrada cuelgan dos pizarras pequeñas en las que se enumera el menú del día o la promoción en español: "pagan 2 comen 3 ".

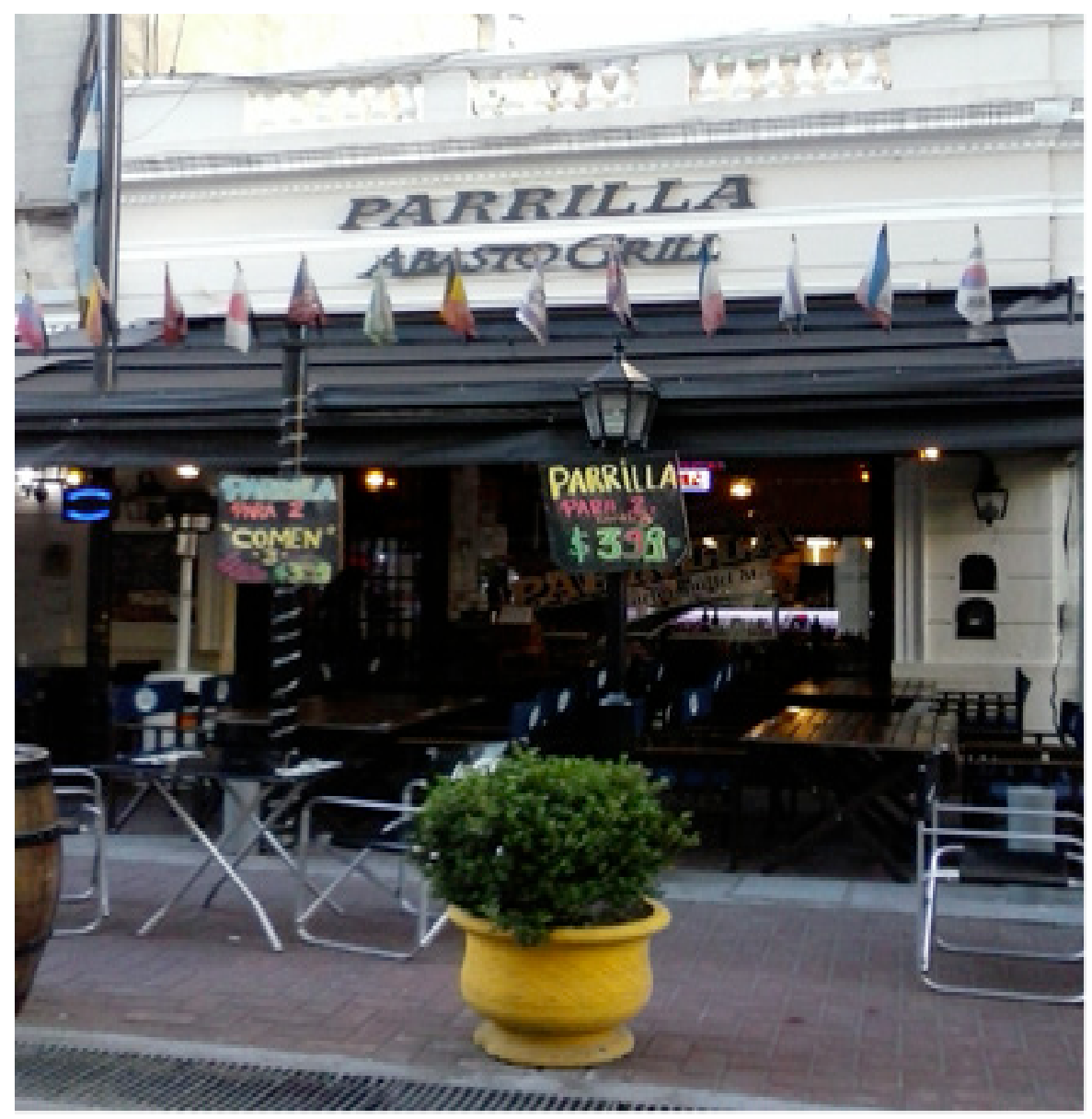

Imagen 6. Frente de parrilla del Pasaje Carlos Gardel, Balvanera 
El uso de las lenguas en esta fachada expresa la noción del inglés como lengua internacional, ya que a través de ella se busca atraer a clientes extranjeros. Pero también demuestra que ese acceso al inglés es desigual. All inclusive (Imagen 7) es una expresión que corresponde a los viajes y la hotelería en la que todos los servicios están incluidos en el monto que se pagó al contratar el viaje. Este no es el concepto exacto que se quiere indicar en ese cartel: se quiere aclarar que cada plato incluye solamente una gran variedad de guarniciones, pero no todas las otras posibles consumiciones. La frase actúa no como un signo lingüístico, sino como un signo semiótico (Blommaert 2010: 28-32): simboliza que se trata de un lugar accesible al turismo.

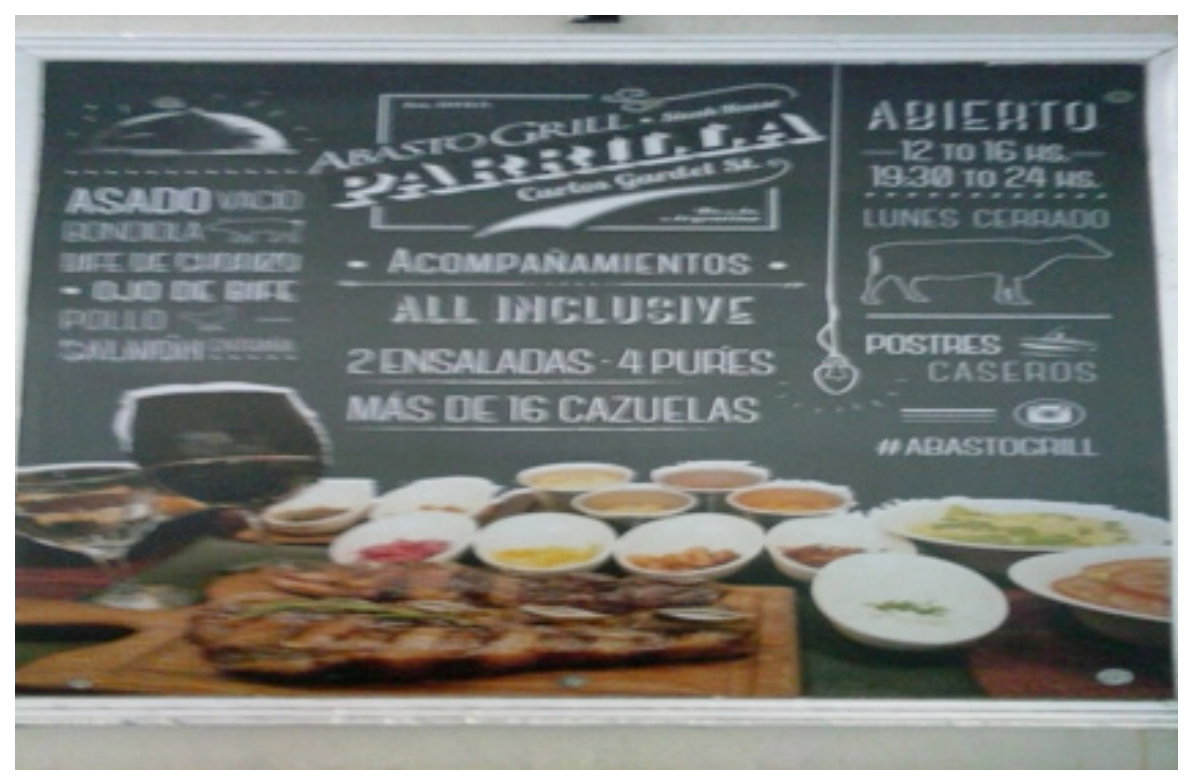

Imagen 7. Cartel de la misma parrilla

En esta misma dirección, en múltiples vidrieras y carteles (Imagen 8) aparecen palabras en inglés como valet parking, un préstamo, entendido como los casos de alternancia de código en el que el léxico es incorporado con mayor frecuencia en los discursos de los hablantes (Auliso y Peralta Frías 2013). 


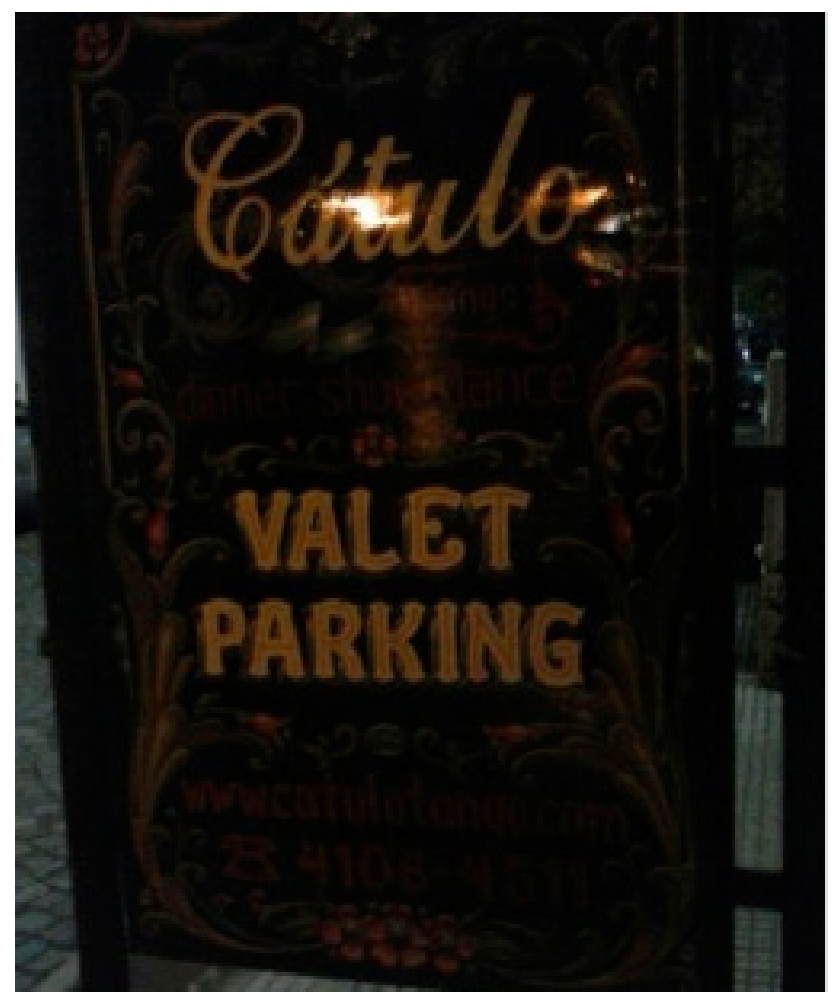

Imagen 8. Cartel de la vereda de un local de tango de Balvanera

También registramos escritos que alternan la lengua sajona y el español en los nombres de los comercios: Arcangel Tattoo, Abasto Store, Pino Show, entre otros. En muchas ocasiones se nombra a los locales en inglés pero no de acuerdo con las formas de composición de palabras de esta lengua. Generalmente, en estos casos se siguen las reglas gramaticales del español y no del inglés (por ejemplo, en esta última lengua los adjetivos siempre anteceden a los sustantivos). Por ejemplo, esto sucede en Health Visual o World Pet. En otros casos la palabra no sigue con la ortografía inglesa como Mistic. Así como en el cartel de la parrilla, se expresa la representación del inglés como lengua de acceso al mundo, como valor. Al mismo tiempo, se evidencia que se trata de una lengua cuyas reglas de conformación de palabras se desconoce, lo que pone de manifiesto el acceso desigual a las lenguas extranjeras.

Es posible vincular la presencia de otras lenguas con el rubro de los locales, especialmente, en lo que respecta a los alimenticios. Esto además se vincula con la función simbólica de internacionalización de las lenguas. Por ejemplo, la heladería se presenta con carteles en italiano. Así, la lengua busca despertar en la asociación de que los productos que se venden en estos comercios guardan la misma calidad que la del país en la que fueron originados o que son referentes en su manufactura o producción.

Frente al Shopping Abasto encontramos un local comercial (Imagen 9) que presenta su cartelería con inscripciones en chino, en alfabeto chino y en latino, sin traducción al castellano. Si bien no son muchos, este comercio no es el único local de ropa chino. Se evidencia a partir de la cartelería la presencia de la comunidad china en el barrio, así como también se hacía de manera oficial con el cartel de la comisaría. 


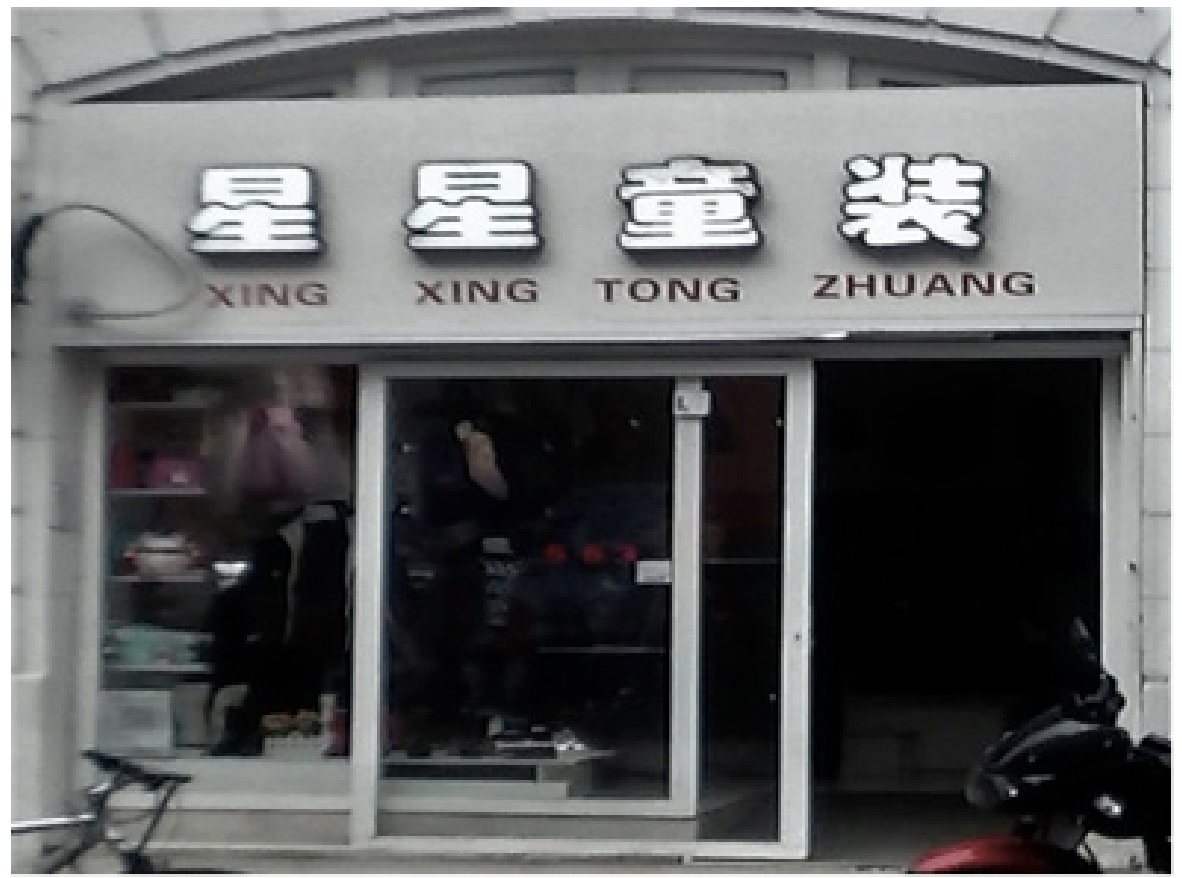

Imagen 9. Comercio ubicado en la calle Anchorena y el Pasaje Carlos Gardel

Asimismo, en los últimos diez años comenzaron a llegar inmigrantes africanos al país y, como mencionamos, muchos de ellos se instalaron en Balvanera. Suelen dedicarse a la venta callejera y cuando hablan entre ellos es posible escuchar lenguas africanas de los países de origen de estos inmigrantes. En el paisaje lingüístico escrito, encontramos el nombre de un local comercial (Imagen 10). Se trata de un maxikiosco que también vende comidas rápidas, cuyos dueños son africanos. El nombre lo refleja: TOUBA ARGENTIN ${ }^{4}$. Entre los platos que ofrece figura el shawarma, plato típico de Medio Oriente. Es notorio que debajo del nombre árabe en alfabeto latino, aunque sea muy difundido, entre paréntesis, se aclare de qué se trata "carne de cordero".

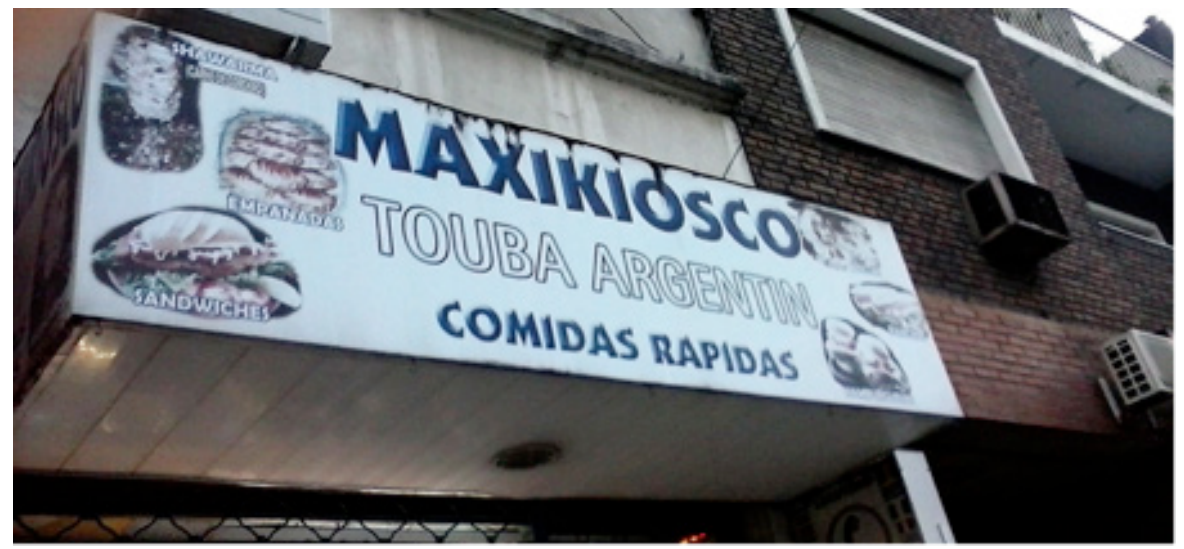

Imagen 10. Cartel de maxikiosco de Balvanera 


\subsection{El paisaje lingüístico del barrio de Flores}

Uno de los barrios más antiguos de la Capital Federal es Flores, que se incorpora en 1888 a la ciudad. En la parte sur de este vecindario se asentó la comunidad coreana que llegó al país desde mediados de la década del 60 , siendo los años 90 el momento en el que se registró el mayor número de migrantes provenientes de ese país. Esta área es comúnmente denominada como "barrio coreano", que se extiende entre las calles Avenida del Trabajo, Carabobo, Avenidas Castañares y La Plata (Courtis, de la Fuente, Domínguez 2010). Allí los migrantes coreanos se reagruparon e instalaron instituciones como las iglesias en torno a las cuales se desarrolló la socialización de las familias inmigrantes (Sassone y Mera 2007). Su extensión se ha ido reduciendo con el tiempo y los inmigrantes y descendientes de inmigrantes se trasladaron a otros barrios como Floresta y a Balvanera. Con el objetivo de analizar la cartelería de los comercios de la zona hemos recorrido la principal calle en la que se ubican los negocios, la Avenida Carabobo desde la altura 600 hasta el 1800.

En todos los locales coreanos hay presencia de esta lengua. Registramos diferentes formas de organizar la distribución de las lenguas en el espacio público. En la mayoría de los casos predomina el coreano, mientras que el español se utiliza para indicar el rubro, en correspondencia con la legislación sobre presencia de lenguas en la ciudad. Por ejemplo, en los templos religiosos de cultos tradicionales de Corea (Imagen 11), el coreano es la primera lengua y debajo de ella se encuentra la aclaración en español.

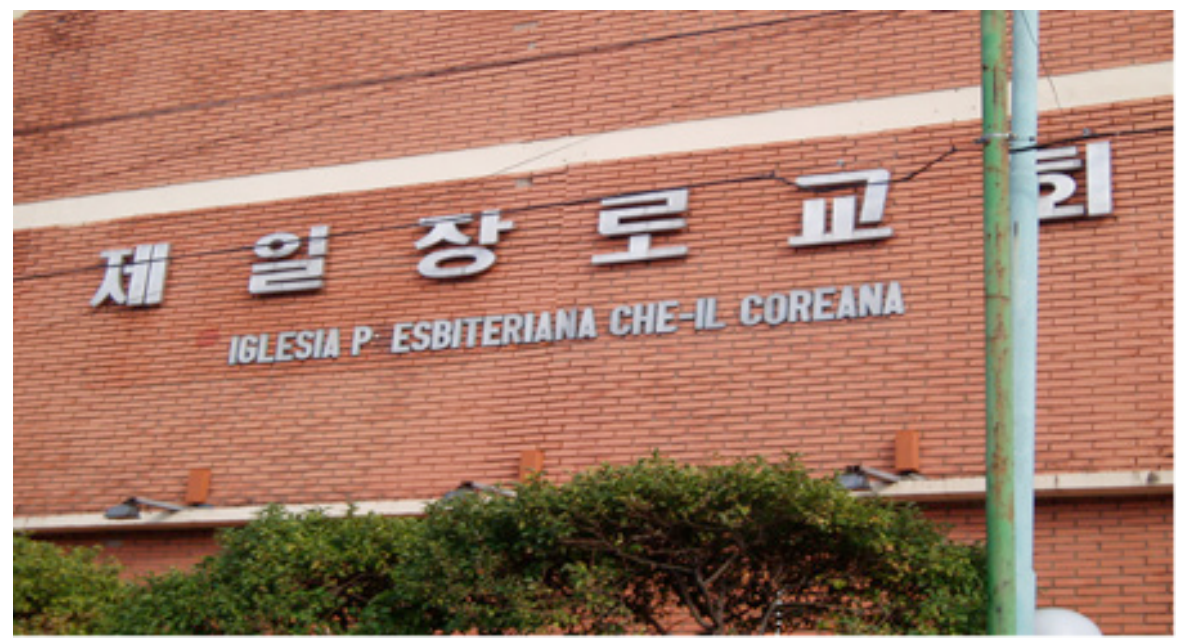

Imagen 11. Frente de templo coreano de Flores

En otros casos, el coreano es la única lengua que se utiliza. En general, se trata de locales pequeños que no tienen carteles sino únicamente inscripciones en la vidriera o sobre puertas, como es el caso de estacionamientos o galpones. Solo un comercio tiene toldo de lona con inscripciones en coreano. En otros comercios (Imagen 12), el español y el coreano aparecen con la misma jerarquía. En una cara del cartel o de la vidriera hay palabras en coreano y en el otro, como en espejo, hay palabras en español. 


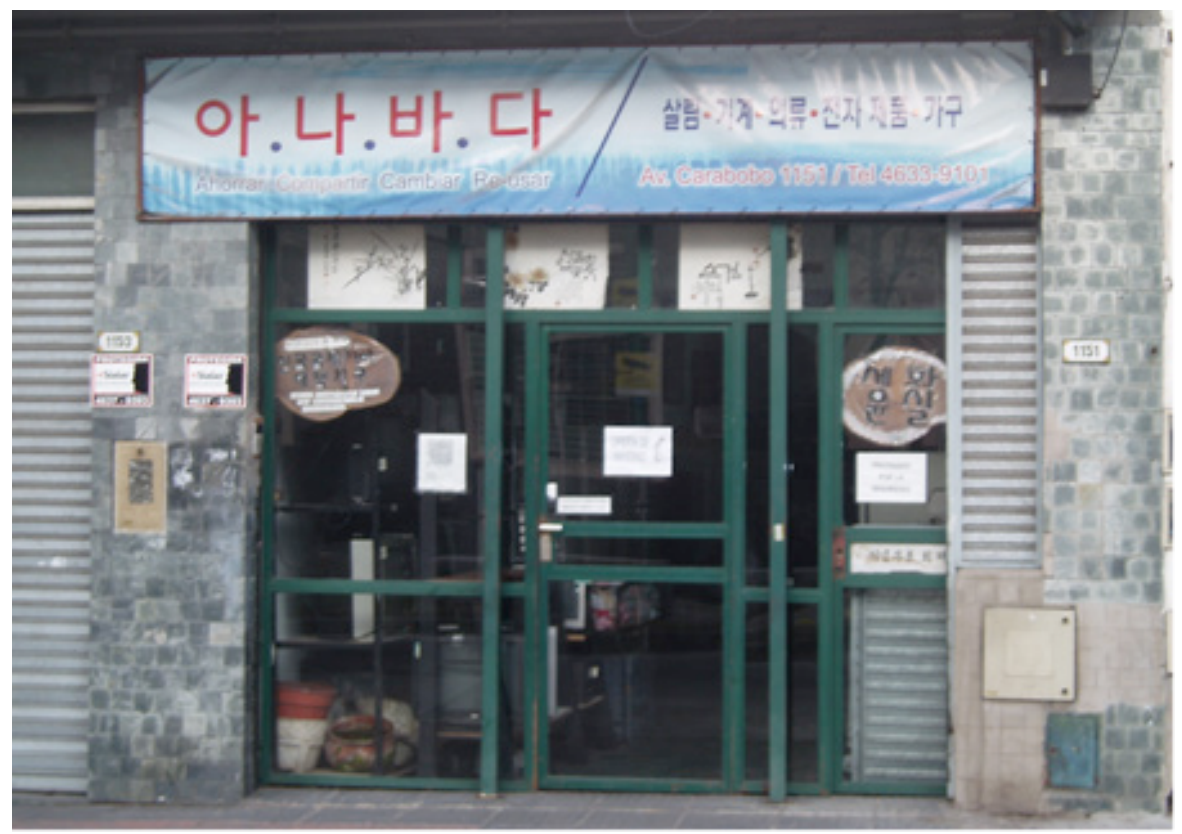

Imagen 12. Frente de local de compra venta de productos usados de Flores

Notamos un supermercado, el más grande de la cuadra, en el que predomina el español. Se utiliza para señalizar productos y ofertas. Esta prevalencia puede interpretarse como la búsqueda por dirigirse a clientes no coreanos.

En la vía pública se encuentran carteles trilingües. Un comercio que se dedica a la importación (Imagen 13) tiene presencia mayoritaria de coreano, pero el nombre está en inglés y el rubro del local también está aclarado en español. Si nos detenemos en la lengua sajona, encontramos problemas con las clases de palabras que se utilizan para la construcción de las frases; esto es similar a lo que sucedía en los locales del Abasto. Nuevamente, el inglés cumple la función de señalar al mundo comercial capitalista; esa lengua parece ser concebida como vehículo de prestigio, internacionalización y calidad frente al coreano y el español.

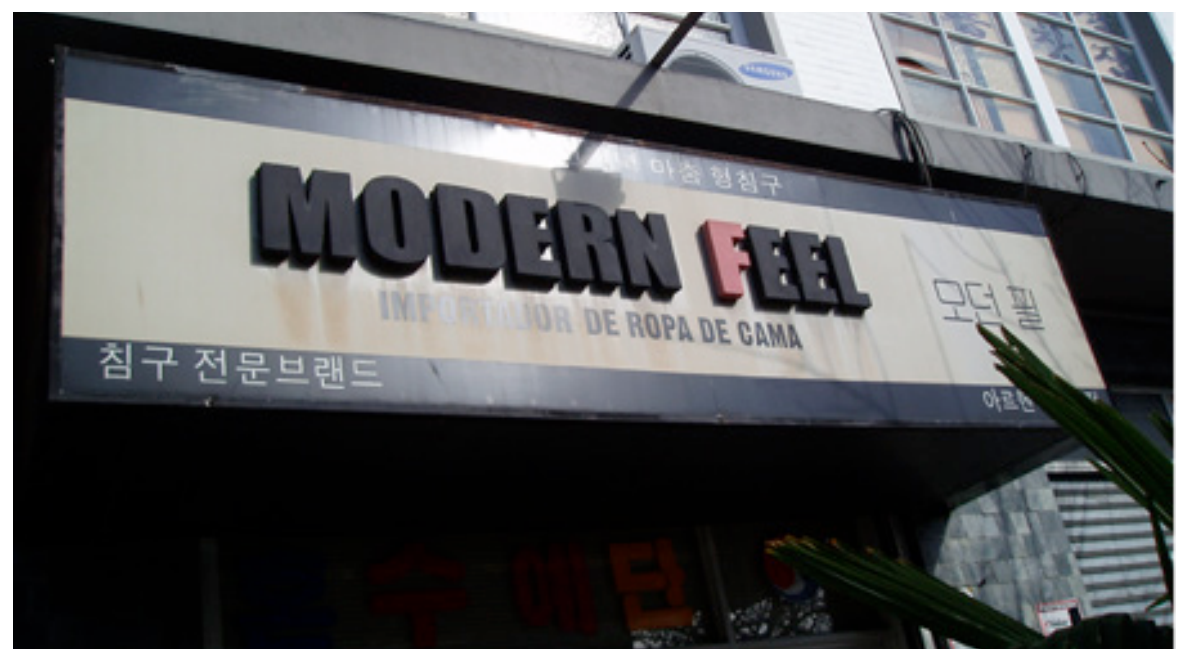

Imagen 13. Cartel de empresa coreana de Flores 
Dos restaurantes (Imagen 14) utilizan el coreano, el chino y el español en su fachada. El primer lugar lo ocupa el coreano, que se encuentra en la puerta y en una de las ventanas de la vidriera. Allí dice el nombre del restaurante y la comida en la que se especializa. Esta lengua indica que se trata de un local perteneciente a la comunidad coreana. En segundo plano se encuentra el chino, que repite la información coreana una sola vez pero en paralelo a la escritura de la vidriera. La presencia de chino marca que el comercio incluye a los miembros de la comunidad china entre sus clientes. Es además una huella de la presencia de inmigrantes chinos en el barrio. En las dos ventanas de los costados se utiliza el español para indicar la dirección y el teléfono; en la opuesta, figura el rubro en español. De esta manera se ajusta a la normativa porteña. En esta parte también se incluye el nombre del local (Baik Ku Samgyupsal).

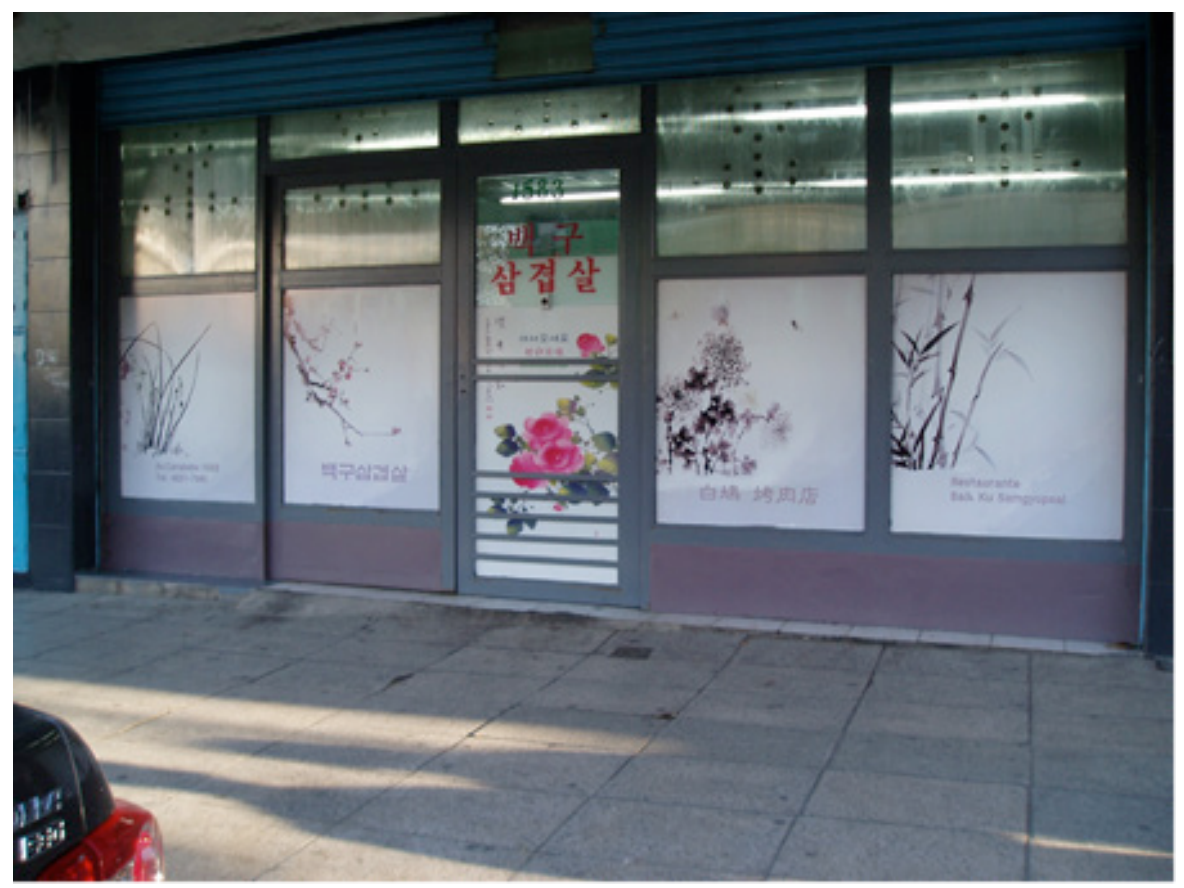

Imagen 14. Frente de restaurante coreano de Flores

Los estudios del paisaje lingüístico nos invitan a rastrear las diferentes lenguas que tienen presencia, la forma de organizarlas, las funciones que cumplen y las representaciones que se les adjudican. Analizar, en contraposición, qué lenguas no tienen lugar en el espacio público también es relevante. En este barrio registramos que no hay presencia escrita de las lenguas indígenas habladas por los migrantes bolivianos, quienes viven en las zonas aledañas (Canelo 2012) y que asisten a las escuelas de la zona (Dirección General de Estadística y Censos GCBA 2012): el quechua, el aymara y el guaraní.

\section{Conclusiones}

A partir del relevamiento del paisaje lingüístico de calles y avenidas centrales de la zona del Abasto de Balvanera y de la zona del barrio coreano de Flores pudimos dar cuenta de la diversidad lingüística que expresa y resulta de la confluencia de procesos migratorios, las áreas turísticas y la 
globalización. Así, se hacen presentes las lenguas de la comunidad judía y de la comunidad coreana en los barrios respectivos. Esta presencia da cuenta de que las comunidades utilizan estas lenguas en forma escrita e identifica a los grupos hablantes. También expresa el valor simbólico que se les da a estas lenguas. Ahora bien, no todos los grupos migratorios tienen el mismo poder de apropiación del espacio público. En este sentido, registramos la ausencia de las lenguas de pueblos originarios que se hablan en Perú y las que se hablan en Bolivia y Argentina, como el quechua, aymara y guaraní. Y esta ausencia puede ser interpretada con el menor estatus y valor que suele asignarse a estas lenguas. No acceden a tener una presencia escrita en el espacio público.

En cuanto al inglés, son varias las operaciones que pudimos analizar. Por un lado, se utiliza la lengua sajona como un índice de un producto de calidad. Por otro lado, cumple el rol de interpelar a los turistas; es decir, se la utiliza en áreas turísticas para atraerlos como clientes. Y, finalmente, su presencia señala la distribución vertical de esta lengua extranjera cuando no actúa principalmente como un signo lingüístico, sino como un emblema del valor positivo atribuido al "mundo anglosajón". En todos estos casos, se construye la representación del inglés como una lengua prestigiosa, valorada y deseada.

En oposición a esta organización in vivo de las lenguas (Calvet 1997), la legislación vigente de la ciudad expresa un nacionalismo lingüístico que se propone frenar la presencia de las lenguas extranjeras y ante la diversidad que supone la globalización busca defender el castellano, si bien acepta términos extranjeros en la publicidad y en los carteles siempre y cuando estén traducidos. Esta normativa se aplica en la señalética de las comisarías de Balvanera que presentaban la palabra "policía" en inglés, chino y hebreo, reconociendo zona como turística a la vez que señalaban la presencia de la comunidad judía y china; luego, con la formación de la policía de la Ciudad de Buenos Aires se pasó a reconocer el área, según las lenguas presentes en la cartelería como zona turística a través de la presencia de las lenguas europeas.

En suma, el análisis del paisaje lingüístico representa un gran aporte para los estudios de las situaciones de plurilingüismo y las representaciones de las lenguas porque "parece reflejar el poder y estatus relativo de los diferentes grupos de lenguas en un contexto específico" (Gorter 2013, 202). 


\section{Q Bibliografía}

" Arnoux, Elvira y Roberto Bein. 1999. “Las representaciones del lenguaje”. En Prácticas y representaciones del lenguaje, editado por Elvira Arnoux y Roberto Bien, 9-10. Buenos Aires: EUDEBA.

» Arrosi, Fabia. 2015. “Introducción”. En Manual de legislación lingüística para docentes, editado por Roberto Bein, 3-10. Proyecto UBACyT 2011-2017 "El derecho a la palabra: perspectiva glotopolítica de las desigualdades/diferencias", dirigido por Elvira Narvaja de Arnoux. http://www.linguasur.com.ar/panel/archivos/8e7b4dd361b63f707ab82oa8cs 95f447manual-para-docentes.pdf

»Auliso, Hebelén y Cecilia Peralta Frías. 2013. "Préstamos léxicos en los menús de los restaurantes de la ciudad de Córdoba". Síntesis 4. Córdoba: Facultad de Filosofía y Humanidades de la UNC. Fecha de consulta, 10 de junio de 2019. https://revistas.unc.edu. ar/index.php/sintesis/article/view/12232/12561

» Blommaert, Jan. 2010. "A messy new Marketplace". En The Sociolinguistics of Globalization. 28-61. Cambridge: Cambridge University Press.

"Blommaert, Jan. 2016. "The conservative turn in linguistic landscape". Fecha de consulta, 20 de enero de 2017. https://alternative-democracy-research.org/2016/01/05/theconservative-turn-in-linguistic-landscape-studies/

》Blommaert, Jan e Ico Maly. 2016. "Ethnographic Linguistic Landscape Analysis and Social Change. A case of Study". En Language and Superdiversity, editado por Karel Arnaut, Jan Blommaert, Ben Rampton y Massimiliano Spotti, 191-211. New York: Routledge.

» Bonnin, Juan Eduardo. 2018. "Invisible landscapes. Diversity and the semiosis of space. En Discourse and Mental Health. Voice, inequality and resistance in medical settings. 66-91. New York: Routledge.

»Calvet, Louis Jean. 1997. Las políticas lingüísticas. Buenos Aires: Edicial.

"Canelo, Brenda. 2012. Fronteras internas. Migración y disputas espaciales en la Ciudad de Buenos Aires. Buenos Aires: Antropofagia.

"Cerruti, Marcela. 2005. "La migración peruana a la Ciudad de Buenos Aires: su evolución y características". Población de Buenos Aires. Buenos Aires: Dirección General de Estadística y Censos. 2, Vol. 2: 7-28. Fecha de consulta, 5 de junio de 2019. http://www. redalyc.org/articulo.oa?id=74020201

"Courtis, Corina, Lisandro de la Fuente e Irupé Domínguez. 2010. "Espacio, discurso y etnicidad: el caso del barrio coreano". Revista Topia. junio.

"Dirección General de Estadística y Censos GCBA. 2017. Migraciones. Año 2015. Ministerio de Hacienda.

»Dirección General de Estadística y Censos GCBA. 2012. Anuario de Estadística Educativa de la Ciudad Autónoma de Buenos Aires. Ministerio de Hacienda del Gobierno de la Ciudad Autónoma de Buenos Aires.

" Feierstein, Ricardo. 2006. Historia de los judíos argentinos. Buenos Aires: Galerna.

" Gorter, Durk. 2013. "Linguistic Landscape in a Multilingual World”. Annual Review of Applied Linguistic. Cambridge: Cambridge University Press. 33: 190-212.

" Honorable Concejo deliberante de la Ciudad de Buenos Aires. 1994. Ordenanza Nº 48965 . 
»Itagi, N. H. y Shailendra Kumar Singh. 2002. Linguistic landscaping in India with particular reference to the new states: proceedings of a seminar. Mysore: Central Institute of Indian Languages and Mahatma Gandhi International Hindi University, New Delhi.

»Landry, Rodrigue y Richard Bourhis. 1997. "Linguistic Landscape and Ethnolinguistic vitality: an empirical study". Journal of Language and Social Psychology. Vol 16: 23-49.

"Legislatura de la Ciudad Autónoma de Buenos Aires. 2000. Ley “Idioma” № 477.

»Pan, Lin. 2007. "Dissecting Multilingual Beijing: The Space and Scale of Vernacular Globalization”. Working Papers in Language Diversity. Jyväskylä: Jyväskylä University. 6. Fecha de consulta: 28 de marzo de 2019.

"Sassano, Silvana. 2001. "Transformación de un espacio urbano: El caso del Mercado de Abasto de Buenos Aires". Anales de Geografía de la Universidad Complutense. 2001, 21: 99-118.

"Sassone, Susana y Carolina Mera. 2007. "Barrios migrantes en Buenos Aires: Identidad, cultura y cohesión territorial”. Actas del V Congreso Europeo CEISAL de latinoamericanistas "Las relaciones triangulares entre Europa y las Américas en el Siglo XXII: Expectativas y desafíos". Bruselas.

» Scherlis, Gabriela. 2018. "El ídish y las lenguas. El paisaje lingüístico del Idishe Visnshaptlejer Institut- Instituto de Investigaciones Judías (IWO)". Coloquio 46. Fecha de consulta: 10 de junio de 2019. http://congresojudio.org/uploads/coloquio/313/coloquio_version_descarga.pdf

"Sinisi, Liliana. 1999. “La relación nosotros-otros en espacios escolares ‘multiculturales'. Estigma, estereotipos y racionalización." En "De eso no se habla..." Los usos de la diversidad sociocultural en la escuela, compilado por María Rosa Neufeld y Jens Ariel Thisted, 189-234. Buenos Aires: EUDEBA.

"Struminger, Benda. 2017. "Los manteros senegaleses, otra cara del conflicto por la venta ambulante”. La Nación. 13 de enero. Fecha de consulta, 1 de junio de 2019. https://www. lanacion.com.ar/buenos-aires/senegaleses-manteros-nid1975391

"Vertovec, Steven. 2007. "Superdiversity and its implications". Ethnic and Racial Studies. 30 (6): 1024-1054.

"Whorf, Benjamin. 1956. Language, Thought and Reality. Cambridge MA. 